\title{
Advanced Technology Based on New Technological and Organizational Prin- ciples of Spatial Development of Front of Mining Operations at Open Pits SELUKOV Alexei $V$.
}

\author{
Sub-Faculty of Open Pit Mining, T.F. Gorbachov Kuzbass State Technical \\ University, 650000 Kemerovo, Russia
}

\begin{abstract}
With the development of coal deposits Siberia, the open way and justified ways of progressive technologies are researched based on the new technological and organizational principles of spatial development of the front mining operations at open pits.
\end{abstract}

Keywords: methodical positions, structural schemes of mining, quarry field.

\section{Introduction}

Based on a special method of mining and geometric analysis of career fields the parameters of the stages of the queues of mining and technological design of the development systems are determined and the technology of working off of deposits queues at the direction of front of mining operations are created. At the first stage,the stage of testing is performed feats not in front of mining operations stretch across layers to a certain intermediate depth development with predominantly foreign dumping of overburden rocks, and at the second stage-the stage of working off along strike layers until end depth development with a predominantly internal dumping.

\section{Characteristic of the work}

Major drawbacks of the longitudinal system with the development of coal have been discovered and deposits inclined steep fall are putting all overburden to external dumps. These factors in turn cause high stripping ratio and significant land capacity of coal production, loss and ore extracted coal. In general technical policy of manufacturers of coal has a sustainable direction for the increase in internal dumping in the development and inclined steep deposits. These technologies are aimed at the elimination of the above shortcomings of such systems development.

Such schemes working off career fields are possible with cross-technologies, which include technology with the creation of the career of the first stage by P. I. Tomakov, submersible technology, layering technology and block technology [1,2].

When you cross development systems to distinguish two stages of development of mining works:

1) formation of initial career with accommodation stripping on external dumps;

2) development of the main part of the career field's direction stripping on internal dumps.

When developing sweet steep and sloping seams mined-out space, it was considered unavailable for the placement of overburden rocks in primary and main periods of operation, which can be used effectively by changing development procedure career fields and targeted action on the management of mountain development works on the quarry and in. Guidelines when creating development 
systems with internal dumping mode of the current section are:

1. Available to the developed space the current position of mining operations with the longitudinal development systems;

2. Flexible to combined connection of two major systems development, representing decisive for the open method of development of coal: a longitudinal front along reservoirs, as well as cross with front transverse to the extension of layers;

3. The development of a working zone with the selection of intermediate circuits in three-hierarchical levels: I block; II - layer; III - area (divide by level happens to their share participate in the admissions capacity inside dump);

4.Change or no direction of front of mining operations in the dynamics of development career: transverse to the extension or strike;

increasing the concentration of mining operations and purposeful formation of the developed space with intermediate and final contours for the transition from external to partial or full internal dumping; usage of optimization of productions as for technology in general and for individual subsystems career.

5. At the present stage of research on extending the scope of application of new technologies in different mining and geological conditions of the Kuznetsk coal basin, the sum of natural and technological factors for deposits in traditional and new areas of coaloutput are considered.

The essence of transversal technologies for current mode cut with the creation of the career of the first stage consists in the following. On the one hand deposits from the current build quarry limited size up to the project depth of the so - called quarry of the first stage. The main purpose of this career - creating an initial capacity to accommodate overburden when developing remainder of deposits (fig. 1).

Moreover, the quarry of the first stage of constructing with the formation in operative boards in parts of the pit, and from the opposite side a working board career. Moving rocks provide vehicles for mines and minerals (coal) are transported to the surface in places of warehousing and processing. Since the construction of the career of the first stage is quite a long time, to minimize the amount of overburden rocks, transported to external dumps, the parameters of this career should also be the least, except depth. The main advantages of the technology considered in comparison with traditional longitudinal are: smaller land capacity of coal output due to host some of overburden rocks in the developed space; reducing the length of the transportation of overburden rocks;

The disadvantages analyzed technology should include the limitations of the front of mining operations and hard interdependence down hole and moldboard areas of the pit.

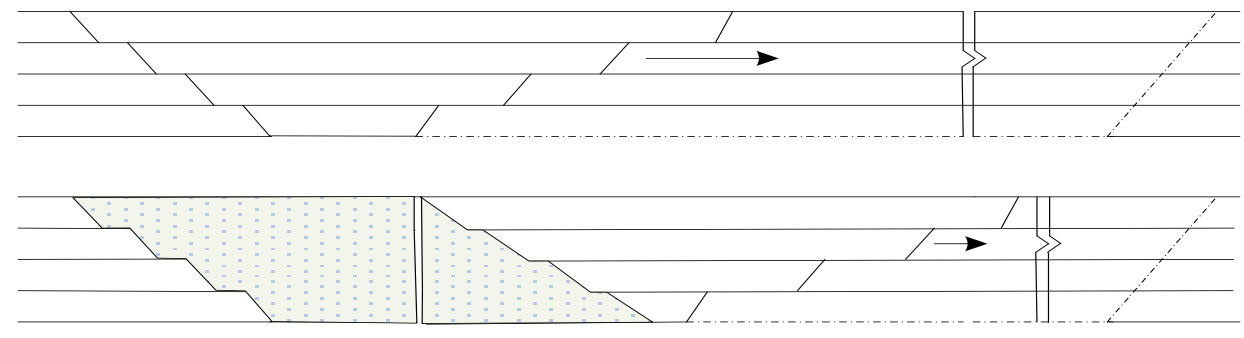

Fig. 1: Cross-technology with the creation of the career of the first stage 
Earlier cross-technology with opencast first stage though and further increases the effectiveness of the open method of coal mining, in comparison with the traditional, but it has some significant drawbacks. The most significant of these is the need of focusing quarry construction of the first stage up to the boundary of depth, which lengthens the period of transition to the internal dumping and causes the violation of large areas of the earth surface external dumps. In addition, I have problems with the reconstruction career when you change the boundary of career paths.

In the Kuznetsk branch of the research institute of the open pit mining and the Kuzbass Polytechnic Institute was designed submersible technology, existence of which is as follows (fig. 2).

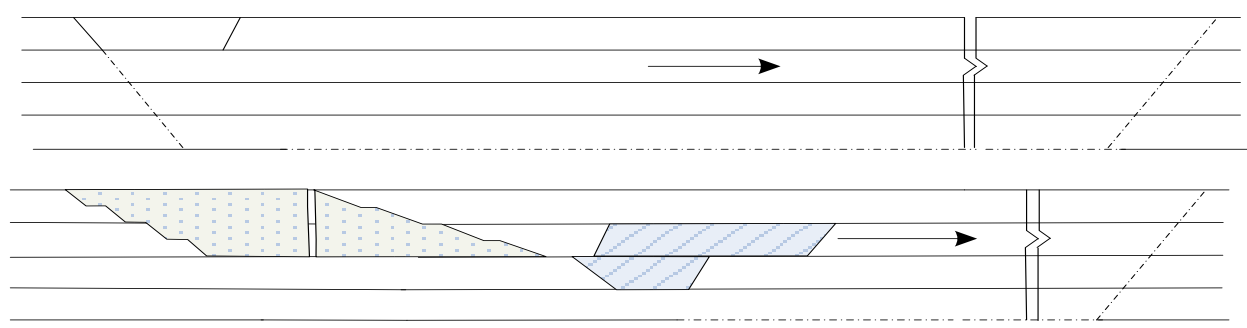

Fig.2: Submersible technology

In one side of coal deposits build on the current depth of the trench transverse to the extension of deposits at a depth equal to the height of the ledge. Rock overburdens are taken to the foreign deposits of the blade. Subsequent testing career produce when stripping the upper (first) of the ledge on the value, determined on the basis of the possibilities for accommodation of overburden of diving into the underlying aquifer. Dive mining is up to the project depth of the quarry. The working area becomes permanent, and all rock overburden moved into the internal dump. The immersion angle varies $16-18^{\circ}$ that determines the stability of the internal dump and time to reach the boundary of the depth of the quarry, which begins working off of deposits with full accommodation of overburden to internal dump. The use of this technology allows reducing the volume of overburden that is hosted on external dumps, and, as consequence, to reduce land capacity of the coal. In addition construction time career and terms of transition to the technology with internal dumping are reduced. When developing the lower horizon may apply non transport technology. A significant disadvantage of this technology is the conservation of a part of reserves when submerged mountain works. Possible field of application longitudinal technology is to develop a suite of coal seams inclined and steep fall of the great length of the strike. Block technology is a further development of transversal technologies with opencast first phase (fig. 3).
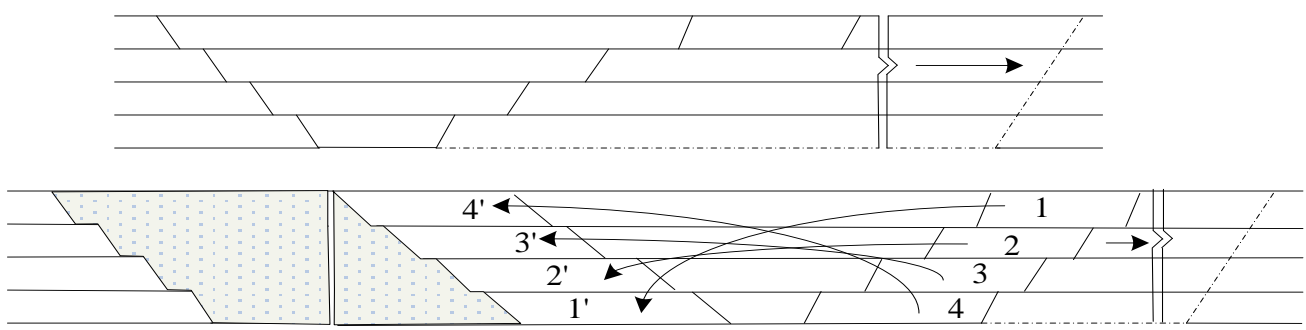

Fig. 3: Block technology 
The distinctive feature of this technology is a division of the field along strike on blocks, including quarry of the first phase and blocks, working on internal dump. The mining operations begin by building a career first and its parameters are established proceeding from the possibilities for accommodation in the new mines all overburden the neighboring block. The block parameters determined on the basis of the following provisions. It is assumed that one unit is fulfilled in one year. This ensures the production capacity of the quarry. Power horizontal layer in a block is set under the terms of minimum losses and dilution during the mining of coal seams mining. The layers in the block work out consistently in descending order, starting from the top of the horizon. The seams mining work excavators type direct and inverse shovel from the hanging sides, that allows reducing the losses of coal and ore its breed. Lying of overburden rocks in the developed space perform horizontal layers, starting from the bottom of waste layer, or inclined layers under the angle of repose, as failover. The advantages of the technology are providing an enabling environment retrieves all the seams mining; placement of overburden rocks in the developed space, high mobility of mining equipment within a layer. The disadvantages include the instability of the current stripping ratio during the year and a large volume of overburden removed to external dumps. Possible field of application technologies development submitted suites coal seams of the complex structure and occurrence with established borders career.

The essence layer technology is the development of the deposit horizontal-governmental layers of differently movement front of works and putting all of overburden in the developed space (fig 4).
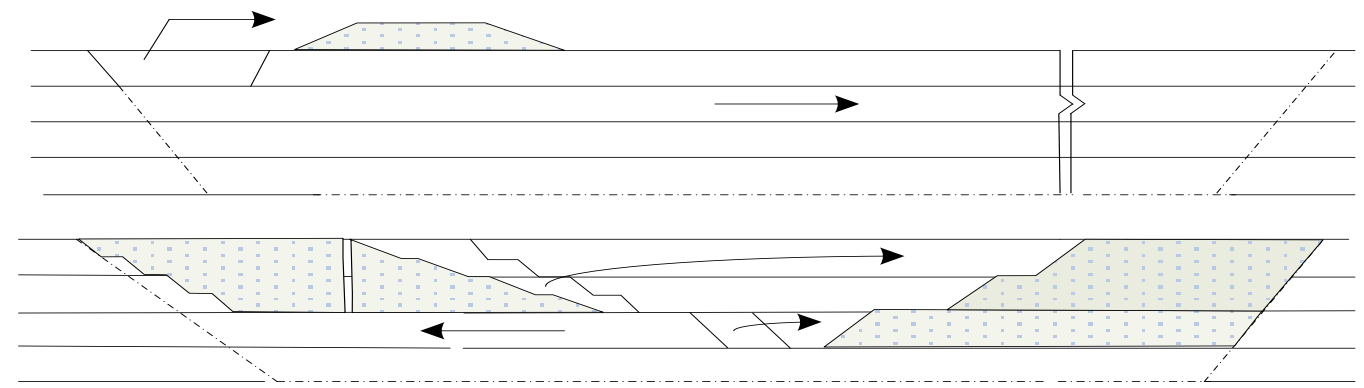

Fig.4: Layer technology

The deposit development starts with facilities in one side of career fields the transverse career digging to a depth of working layer, defined in criterion transportation work when comparing non transport and transport technology of working off of layers. Overburden rocks are placed on the surface of career fields. Possible power working layer reaches 100 meters. Width generation is established on the basis of the possibilities for accommodation of overburden when mining layer in the developed space. The lengths of the working along the bottom are equal to horizontal power mined deposits. After the construction of the cross-career excavation begin to develop the remaining part of the horizontal layer. Development layer produce one high ledge with a breakdown of its height in layers. The refinement of the layer is in descending order, starting from the top. After mastering the first layer are preparing for the development of the underlying layer. To do this in the first layer of the rock with the help of vehicles moving on the surface of the internal dump him. This creates space for the construction of cross 
career development for preparation for the development of underlying aquifer. While under construction production lead to removal of overburden also on the surface of the internal dump him. After the construction of the preparatory mountain developments on the second horizon produce the refinement of the second horizon layer with the placement of overburden rocks in developed-dimensional space of the same horizon. Rock overburden internal dump first horizons move into the internal dump of the same horizons on the inner surface of the blade of the underlying layer. Thus, the direction of the front of works is changed to the opposite direction, i.e. development of the lower layer is in the opposite direction. After the work of the second layer is carried out, if necessary, dive on the third horizon with observance of all technological operations specified when diving on the second horizon. In such sequence mining the horizon is achieved by equality and boundary layer stripping ratios. Feature layer technology is the presence of one of the mining layer. Waste layers are internal dumps, periodically reloaded from one position to another as working off of underplaying layers. Positive aspects of the layer technology are the absence of external dumps, reducing the land capacity of coal mining, the use of non transport technologies when developing layer, which reduces the cost of coal production the placement of overburden in the developed space results a reduction in the length of transportation and, consequently, reduces transport costs. Negative aspects are the need for repeated handling overburden internal dump, which leads to an increase of the stripping ratio. Possible field of application layer technologies are coal deposits of the great length of the strike.

\section{Conclusion}

According to the analysis of geological conditions, in fact, which is applied by technologies open coal mining, the possible technological solutions and requirements for perspective technologies formulated the main principles and methods of formation of structural schemes of the order of testing career fields

\section{References}

[1] Tsepilov I.I., Koryakin A. I., Kolesnikov V. F., Protasov S.I. Perspective technologies of open development complex-structural coal deposits // Kuzbass state technical university, 2000. $-186 \mathrm{p}$.

[2] Tomakov P. I., Kovalenko V.S. Rational land use in open mining // Nedra, 1984. - 213p. 